\title{
Metabolism of Triglyceride-rich Lipoproteins during Alimentary Lipemia
}

\author{
Fredrik Karpe," George Steiner, ${ }^{\star}$ Thomas Olivecrona," Lars A. Carlson, ${ }^{*}$ and Anders Hamsten* \\ *King Gustaf V Research Institute and Department of Internal Medicine, Karolinska Hospital, Karolinska Institute, S-104 01 Stockholm, \\ Sweden; ${ }^{\ddagger}$ Department of Medicine and Physiology, University of Toronto and Division of Endocrinology and Metabolism, Toronto \\ General Hospital, M5G 2 C4 Toronto, Canada; and ${ }^{\S}$ Department of Medical Biochemistry and Biophysics, University of Umeå, \\ S-901 87 Umeå, Sweden
}

\begin{abstract}
The metabolism of chylomicron remnants and VLDL was studied in healthy controls and normo- (NTG) and hypertriglyceridemic (HTG) patients with coronary artery disease after intake of an oral fat load. Specific determination of apo B-48 and B-100 enabled separation of the respective contribution of the two lipoprotein species. The postprandial plasma levels of small (Sf 20-60) and large (Sf 60-400) chylomicron remnants increased in controls and NTG patients. In contrast, only large chylomicron remnants increased in the HTG patients. An increase of large VLDL was seen in response to the oral fat load in all groups, whereas small VLDL were either unchanged in the controls and the NTG patients, or decreased in the HTG patient group. The whole plasma concentration of $\mathrm{C}$ apolipoproteins was essentially uninfluenced by the oral fat load, whereas the content in large triglyceride-rich lipoproteins paralleled the apo B elevations in controls and NTG patients. An even more prominent increase of apo $B$ in large triglyceriderich lipoproteins in the HTG group was not accompanied by an increase of $\mathrm{C}$ apolipoproteins. These findings indicate that chylomicrons compete with VLDL for removal of triglycerides by lipoprotein lipase and that the postprandial metabolism of triglyceride-rich lipoproteins is severely defective in hypertriglyceridemia. (J. Clin. Invest. 1993. 91:748-758.) Key words: chylomicron remnants • very low density lipoprotein - apolipoprotein B-48 - apolipoprotein B-100 - apolipoprotein C-II • hypertriglyceridemia
\end{abstract}

\section{Introduction}

Triglyceride-rich lipoproteins (TGRL) ${ }^{1}$ are a heterogeneous population of lipoprotein particles varying in site of synthesis, structure, and metabolism. VLDL are made in the liver and contain apo B-100 and endogenous lipids. By contrast, ingestion of fat leads to production of chylomicrons containing apo B-48 in the intestine. Synthesis of apo B-100 has recently also been described in the human gut; the quantitative significance of this is, however, still unknown (1). The apo B molecule

Address correspondence to Dr. Fredrik Karpe, King Gustaf V Research Institute, Karolinska Hospital, S-104 01 Stockholm, Sweden. 1992.

Received for publication 2 April 1992 and in revised form 25 August

1. Abbreviations used in this paper: AUC, areas between the curves; CAD, coronary artery disease; HL, hepatic lipase; HTG, hypertriglyceridemic; LPL, lipoprotein lipase; NTG, normotriglyceridemic; Sf, Svedberg flotation rate; TGRL, triglyceride-rich lipoproteins.

J. Clin. Invest.

(c) The American Society for Clinical Investigation, Inc.

0021-9738/93/03/0748/11 $\$ 2.00$

Volume 91, March 1993, 748-758 remains an integral part of the lipoprotein particle, whereas the triglyceride content of TGRL is readily hydrolyzed by lipoprotein lipase (LPL) resulting in formation of remnant particles (2). The family of apo Cs (C-I, C-II, and C-III) and apo E are thought to be transferred from HDL to TGRL during alimentary lipemia (3). Triglyceride hydrolysis by LPL requires apo C-II as cofactor. The roles of apo C-I and C-III in the metabolism of TGRL are less well understood. Apo C-III has been considered both to counteract the lipolysis stimulating function of apo C-II $(4,5)$ and to inhibit the receptor-mediated uptake of TGRL (6-8). The same opposing effect on receptormediated uptake of remnant lipoprotein particles has been shown for apo C-I in vitro (9). Apo E serves as a ligand for binding of TGRL to cellular receptors $(10,11)$. The amount and conformation of apo $\mathrm{E}$ has been shown to be of major importance for cell mediated uptake of hypertriglyceridemic (HTG) VLDL in vitro (10). The isoform of apo $\mathrm{E}$ has also been shown to influence the elimination of chylomicron remnants from plasma $(12,13)$. In particular, the presence of apo E2 delays the clearance of chylomicron remnants. Under normal metabolic conditions, LDL is the end product of the metabolism of VLDL in humans. On the other hand, since no apo B-48 is found in LDL, chylomicrons and their remnants are thought to be removed from plasma earlier in the lipolytic cascade. Because the metabolic end products of TGRL are considered to be involved in atherogenic processes, studies of alimentary lipemia is of major clinical interest (14).

Most previous studies on chylomicron and chylomicron remnant metabolism in humans have used retinyl palmitate as a marker for intestinally derived TGRL (15-17). A delayed clearance of chylomicron remnants has been found in subjects with manifest coronary artery disease (CAD) (18-19). Direct quantification of chylomicron remnants and VLDL by determination of apo B-48 and apo B-100 in TGRL during alimentary lipemia has, however, not been performed before. Therefore we have investigated the generation and catabolism of postprandial chylomicron remnants and the impact of alimentary lipemia on VLDL metabolism in control subjects and in normotriglyceridemic (NTG) and HTG patients with manifest CAD. This was done by conducting an oral fat tolerance test with direct quantification of apo B-48 and B-100 in subfractions of TGRL of different particle size. The impact of some components of lipoprotein particle composition and the influence of lipolytic enzymes were assessed by determining the apo C-I, C-II, C-III, and E concentrations in subfractions of TGRL, the apo E genotypes, and the activities of postheparin plasma LPL and hepatic lipase (HL).

\section{Methods}

Patients and controls. A total of 32 patients with angiographically ascertained CAD who had all survived a first myocardial infarction before the age of $45 \mathrm{yr}$ and who had subsequently participated in an angiographic study of mechanisms associated with progression of coro- 
nary atherosclerosis (20) were enrolled into the study. Patients with polygenic or monogenic hypercholesterolemias (based on repeated lipoprotein classifications showing a type Ila pattern and studies of firstdegree relatives) were not considered. Subjects who were obese ( $\geq 130 \%$ ideal weight), or had manifest diabetes mellitus (repeated fasting blood glucose values $\geq 7.0 \mathrm{mmol} /$ liter), or were taking lipid-lowering medication or abusing alcohol were excluded. Due to these exclusion criteria the patient group comprised 14 normolipidemic subjects and 3 NTG subjects with sporadic hypercholesterolemia and 15 subjects with mild to moderate HTG. Lipoprotein phenotyping was based on the 90th percentiles of VLDL triglyceride $(1.65 \mathrm{mmol} / \mathrm{liter})$ and LDL cholesterol $(5.35 \mathrm{mmol} / \mathrm{liter})$ values in an age- and sex-matched control population (21). None of the patients studied had suffered reinfarction within the preceding 6 mo. Coronary artery bypass grafting had been performed on nine patients with severe exertional angina. More than $1 \mathrm{yr}$ had elapsed between bypass surgery and the present study. A control group comprising 10 normolipidemic men of similar age was recruited from participants in a previous population survey (21). They had initially been drawn from a register containing all subjects permanently living in the county. All controls were free of symptoms and clinical signs of CAD. There was no clinical or laboratory evidence of thyroid dysfunction or other conditions leading to secondary hyperlipoproteinemia in any of the patients or controls studied.

At the time of their myocardial infarction all patients were instructed to follow a diet low in fat, rich in complex carbohydrates, and with a limited intake of alcohol. The percentage composition of the different sources of energy in the recommended diet was $10-15 \%$ protein, $30 \%$ fat, and the remaining energy from carbohydrates. The ratio of saturated to mono- and polyunsaturated fat was $1: 1: 1$.

Oral fat tolerance test. Participants were admitted early in the morning to the Clinical Research Unit for a mixed meal type of oral fat tolerance test. They had been fasting for $12 \mathrm{~h}$ and asked to refrain from smoking during the fasting period and from alcohol intake during the preceding $3 \mathrm{~d}$. The protocol for the fat tolerance test was a slight modification of that of Cohn et al. (22). An emulsion consisting of soybean oil $\left(50 \mathrm{~g} / \mathrm{m}^{2}\right.$ body surface area [23]; Karlshamns Oils \& Fats AB, Karlshamn, Sweden), glucose $\left(50 \mathrm{~g} / \mathrm{m}^{2}\right)$, egg-white protein $\left(0500,25 \mathrm{~g} / \mathrm{m}^{2}\right.$; Sigma Chemical Co., St. Louis, MO), dried egg yolk $\left(0625,6.3 \mathrm{~g} / \mathrm{m}^{2}\right.$; Sigma), and $200 \mathrm{ml}$ water prepared with some lemon flavor $(60.2 \%$ fat, $13.3 \%$ protein, and $26.5 \%$ carbohydrate by energy) was ingested within $10 \mathrm{~min}$ between 7:00 and 7:30 a.m. The test meal was well tolerated by all subjects. Blood samples were obtained through an indwelling catheter. A fasting blood sample was taken before intake of the test meal. Subsequent blood samples were drawn hourly for the first $9 \mathrm{~h}$ and the last sample was taken $12 \mathrm{~h}$ after ingestion of the emulsion. Participants were allowed to be ambulant throughout the test. Smoking was not allowed. Water, but no food, was allowed during the test.

Blood sampling. Venous blood samples were drawn into precooled sterile tubes (Vacutainer; Becton Dickinson, Meylan Cedex, France) containing $\mathrm{Na}_{2}$ EDTA $(1.4 \mathrm{mg} / \mathrm{ml})$, which were instantly put into icewater. Plasma was then recovered within $30 \mathrm{~min}$ by low speed centrifugation $\left(1,750 \mathrm{~g}, 20 \mathrm{~min},+1^{\circ} \mathrm{C}\right)$ and kept at this temperature throughout the preparation procedures. NaAzide ( $1.0 \mathrm{~mol} / \mathrm{liter})$, PMSF (10 $\mathrm{mmol} /$ liter, dissolved in isopropanol), and aprotinin $(1,400 \mu \mathrm{g} / \mathrm{ml})$ (Trasylol; Bayer, Leverkusen, Germany) were immediately added to the isolated plasma before fractionation of TGRL to final concentrations of $1.0 \mathrm{mmol} / \mathrm{liter}, 10 \mu \mathrm{mol} / \mathrm{liter}$, and $28 \mu \mathrm{g} / \mathrm{ml}$, respectively.

Subfractionation of $S f>12$ lipoproteins. TGRL were subfractionated by cumulative rate ultracentrifugation (24) from plasmas drawn before ingestion of the test meal and 3,6, and $12 \mathrm{~h}$ thereafter. Plasma was adjusted to density $1.10 \mathrm{~kg} /$ liter with solid $\mathrm{NaCl}$. A density gradient consisting of $4 \mathrm{ml}$ of $1.10 \mathrm{~kg} /$ liter plasma and $3 \mathrm{ml}$ each of $1.065,1.020$, and $1.006 \mathrm{~kg} /$ liter $\mathrm{NaCl}$ solutions was then formed in tubes (vol 13.4 ml) (Ultraclear; Beckman Instruments, Inc., Fullerton, CA) which had been coated with polyvinyl alcohol (BDH Chemicals Ltd., Poole, UK). Ultracentrifugation was performed in an SW40 Ti (Beckman Instruments, Inc.) swinging bucket rotor at $40,000 \mathrm{rpm}$ and $+15^{\circ} \mathrm{C}$ (L8-55 ultracentrifuge; Beckman Instruments). Consecutive runs calculated to float Sf $>400, \mathrm{Sf} 60-400$, and Sf 20-60 particles were made. After each centrifugation, the top $0.5 \mathrm{ml}$ of the gradient containing the respective lipoprotein subclasses was aspirated and density $1.006 \mathrm{~kg} / \mathrm{liter}$ salt solution was used to refill the tube before the next run. The Sf 12-20 fraction was recovered after the last ultracentrifugal run by slicing the tube $29 \mathrm{~mm}$ from the top after the Sf 20-60 lipoproteins had been aspirated. All salt solutions used to prepare the density gradients were adjusted to pH 7.4 and contained $0.02 \%$ NaAzide and $0.01 \%$ EDTA. Densities were verified to the fourth decimal place (densitometer; Paar, Graz, Austria). Aliquots of the three subfractions of TGRL were immediately placed under $\mathrm{N}_{2}$ and frozen at $-80^{\circ} \mathrm{C}$ for later determination of apo B-48 and apo B-100. The Sf 12-20 subfraction was dialyzed exhaustively against $0.15 \mathrm{M} \mathrm{NaCl}, 0.01 \%$ EDTA, and $0.01 \% \mathrm{NaAzide}$ at $+2{ }^{\circ} \mathrm{C}$, and thereafter frozen. The frozen samples were shipped on dry ice from Stockholm to Toronto no later than $2 \mathrm{wk}$ after they had been isolated.

Determination of apo B-48 and apo B-100. Apo B-48 and B-100 were quantified using an assay which was based on the relative chromogenicities of these apolipoproteins after separation by electrophoresis (25) in SDS-PAGE as described by Kane et al. (26). Aliquots of isolated lipoprotein fractions containing 200-500 $\mu \mathrm{g}$ of total protein (27) were delipidated (28). The delipidated precipitate was dissolved overnight in sample buffer (sodium phosphate $50 \mathrm{mM}$, SDS $1 \%$, and mercaptoethanol $1 \%, \mathrm{pH} 7.2$ ) and applied to $3.3 \%$ SDS-PAGE rod gels. Four or five dilutions of the delipidated lipoprotein sample buffer preparation were run for each sample. A total apo B mass of $\sim 20-60 \mu \mathrm{g}$ was applied to each gel. Gels were stained with Coomassie R-250 (Eastman Kodak Co., Rochester, NY) for $24 \mathrm{~h}$ and then destained for $3 \mathrm{~d}$ in $10 \%$ acetic acid before scanning. Scanning was performed by a laser densitometer (Ultroscan; Pharmacia LKB Biotechnology AB, Uppsala, Sweden) linked to an Apple Ile personal computer (Apple, Cupertino, CA), and the area under each peak was integrated automatically by the instrument with the use of the Gelscan software package (Pharmacia LKB Biotechnology $\mathrm{AB}$ ). Graphs relating the intensity of staining (area under the scanning curve) for the apo B-48 and B-100 peaks to the lipoprotein sample dilution were constructed. The relative amounts of the two molecular forms of apo B in the sample could then be calculated. The absolute masses of apo B-48 and B-100 were derived from their relative quantities and the total apolipoprotein $B$ mass. The latter was quantified in all fractions of TGRL and in the Sf 12-20 fraction by electroimmunoassay after pretreatment of samples with lipase (29). The intra- and interassay coefficients of variation were 2.7 and $2.1 \%$ respectively, for the two molecular forms of apo B (25). The lower quantification limit on the gel was $2 \mu \mathrm{g}$ apo B.

Determination of apo C-I, C-II, C-III, and E. Whole plasma concentrations and concentrations of apo C-I, C-II, C-III, and E of lipoprotein fractions (Sf $>400$, Sf 60-400, Sf 20-60 and Sf 12-20) were determined in triplicate by an enzyme immunoassay (30). The validity of this method for use on postprandial plasma lipoproteins has been demonstrated previously (31).

Apo E genotyping. DNA was extracted from fresh blood samples by the Triton X-100 lysis method (32). The restriction isotyping procedure (PCR amplification on an intelligent heating block [Cambio, Cambridge, UK], digestion with the enzyme Hhal, and electrophoresis on polyacrylamide gels) was then applied as described by Hixson and Vernier (33). Oligonucleotide primers used in the PCR were as previously described (34).

Determination of $L D L$ and $H D L$. The cholesterol and triglyceride content of LDL and HDL was determined by a combination of preparative ultracentrifugation and precipitation of apo B-containing lipoproteins followed by lipid analyses as described (35). The "LDL fraction" determined by this method is actually composed of intermediate density lipoprotein and LDL and may contain lipoprotein (a).

Lipid analyses. Total cholesterol and triglycerides were determined in triplicate in plasma and in the major plasma lipoproteins. For quantification of cholesterol and triglycerides in plasma, HDL, and LDL, lipids were first extracted with chloroform-methanol (36). Cholesterol (37) and triglycerides (38) were then determined on an Ultrolab (Phar- 
macia LKB). Triglycerides and cholesterol in isolated fractions of TGRL were determined by enzymatic methods (877557; Boehringer Mannheim Diagnostica, Mannheim, Germany, and 14106-14108, Merck Diagnostica, Darmstadt, Germany).

Postheparin plasma lipase activities. An intravenous injection of heparin $(100 \mathrm{U} / \mathrm{kg}$ body $\mathrm{wt})$ was given at a separate visit $1 \mathrm{wk}$ after the oral fat tolerance test. Fasting venous blood for determination of postheparin plasma LPL and HL activities was drawn before and $15 \mathrm{~min}$ after the heparin injection from the other arm. Assay conditions for LPL (sonicated emulsion of $\left[{ }^{3} \mathrm{H}\right]$ oleic acid-labeled triolein in $20 \% \mathrm{In}$ tralipid ${ }^{\oplus}$ [Kabi Pharmacia Parenterals, Stockholm, Sweden]) and HL (sonicated emulsion of ${ }^{3} \mathrm{H}$-labeled triolein in gum arabic) were the same as described by Peterson et al. (39). All determinations were done in triplicate. For assay of LPL, samples were preincubated ( $2 \mathrm{~h}$ on ice) with 0.5 vol of goat antiserum to HL to suppress HL activity. For assay of HL, LPL was inhibited by a high salt concentration in the assay medium. Lipase activities were expressed in $\mathrm{mU} / \mathrm{ml}$, which corresponds to $1 \mathrm{nmol}$ of fatty acid released per minute per volume of postheparin plasma.

Statistical analysis. Conventional methods were used for calculation of means and standard deviations. Statistical significance for differences in continuous variables between more than two groups was tested by one-way ANOVA. The Scheffe F test was used to identify differences among the groups when the overall $F$ statistic was significant. Within group comparisons of measurements made at various time points during the test were done by Student's paired $t$ test. To estimate the overall response of lipid and lipoprotein components present in the plasma during the entire 12-h postprandial period, areas between the curves (AUC) for plasma measurements plotted against time after the test meal and the $x$ axis were calculated.

Ethical considerations. The experimental protocol was approved by the ethical committee of the Karolinska Hospital, Stockholm. All subjects gave their informed consent to participate in the study.

\section{Results}

Basic characteristics of the study groups. The distribution of subjects between apo E genotypes and oral glucose tolerance categories, postheparin plasma lipase activities, and body mass indices are shown in Table I. The apo E $3 / 3$ genotype dominated in all groups. Seven subjects were heterozygous for the apo E2 allele, three belonged to the control group, three to the NTG patient group, and one to the HTG patient group. There were no subjects homozygous for the E2 allele. No subject with decreased oral glucose tolerance was found in the control group, whereas two NTG and six HTG patients had decreased oral glucose tolerance. Postheparin plasma LPL activity was significantly lower in the HTG patient group than in the NTG patient and the control groups. In contrast, the HTG subjects had significantly higher HL activity compared with the NTG patient group. The body mass index was somewhat higher in the HTG patient group.

Fasting plasma lipoproteins. Plasma concentrations of cholesterol, triglyceride, apo B-100, and apo B-48 in TGRL, and plasma concentrations of cholesterol and triglycerides in LDL and HDL are given in Table II. The levels of cholesterol, triglyceride, and apo B-100 were markedly elevated in the fractions containing large (Sf 60-400) and small (Sf 20-60) TGRL particles in the HTG group as a consequence of the criteria for selection of the HTG patients. The large TGRL particles in the HTG patient group appeared to be enriched in both cholesterol and triglyceride, since the ratios between lipid parameters and apo B-100 were elevated when compared with these ratios in the controls and the NTG patients. The apo B-100 concentration in the Sf 12-20 range, namely the IDL particle number,
Table I. Basic Characteristics of the Study Groups

\begin{tabular}{lccc}
\hline & Controls & $\begin{array}{c}\text { NTG } \\
\text { patients }\end{array}$ & $\begin{array}{c}\text { HTG } \\
\text { patients }\end{array}$ \\
\hline & $n=10$ & $n=17$ & $n=15$ \\
Age (year) & $49.2 \pm 3.6$ & $48.8 \pm 3.5$ & $48.7 \pm 3.6$ \\
Body mass index $\left(\mathrm{kg} / \mathrm{m}^{2}\right)$ & $24.5 \pm 2.8$ & $25.8 \pm 3.8$ & $27.7 \pm 3.0$ \\
Oral glucose tolerance* & & & \\
Normal & 7 & 9 & 4 \\
Borderline & 3 & 6 & 5 \\
Decreased & 0 & 2 & 6 \\
Apo E genotype & & & \\
E3/E2 & 2 & 1 & 2 \\
E3/E3 & 6 & 11 & 8 \\
E3/E4 & 1 & 5 & 3 \\
E4/E2 & 1 & 0 & 1 \\
E4/E4 & 0 & 0 & 1 \\
Postheparin plasma lipase & & & \\
$\quad$ activities & & & \\
LPL & $483 \pm 180$ & $431 \pm 146$ & $303 \pm 80^{\ddagger}$ \\
HL & $338 \pm 128$ & $280 \pm 113$ & $416 \pm 175^{5}$ \\
\hline
\end{tabular}

Values are mean $\pm S D$ or number of subjects in group. Analysis of variance: The Scheffe $F$ test was used to identify differences among the groups when the overall $F$ statistic was significant.

* The oral glucose tolerance was assessed according to Reaven et al. (40). ${ }^{\ddagger} P<0.05$ compared with both controls and NTG patients; ${ }^{\S} P<0.05$ compared with NTG patients.

was similar in all groups, whereas the IDL particles in the HTG patient group contained almost 50\% more cholesterol compared with both the controls and the NTG patient group. Apo B-48 was detected in the fasting state in all groups. In fasting samples of the Sf $60-400$ fraction, $67 \%$ of the HTG patients, $35 \%$ of the NTG patients, and $50 \%$ of the control subjects had apo B-48 levels clearly above the quantification limit $(>0.2$ $\mathrm{mg} / \mathrm{liter}$ ). In the Sf 20-60 fraction the corresponding figures were 93,71 , and $70 \%$, and in the Sf $12-20$ fraction, 53, 47, and $40 \%$. Only four of a total of 42 subjects completely lacked measurable apo B-48 in all TGRL fractions of the fasting plasma sample. The fasting level of apo B-48 was significantly elevated in the Sf 60-400 and Sf 20-60 fractions of the HTG patients compared with both controls and NTG patients.

No statistically significant differences were found between the groups for fasting plasma LDL cholesterol or triglyceride concentrations. The HDL cholesterol level was lower than in controls in both patient groups.

Postprandial responses of triglyceride-rich lipoproteins. The plasma concentrations of triglycerides, apo B-48, and apo B-100 in TGRL after intake of the oral fat load are shown in Table III and illustrated further in Fig. 1. The fasting and postprandial plasma concentrations of apo B-48 in the Sf $>400$ fraction were frequently low and quantification could only be made in 18:42 subjects (data not shown). Similarly, triglyceride levels in the $\mathrm{Sf}>400$ fraction of fasting plasma were low in all groups. $3 \mathrm{~h}$ after intake of the fat load the triglyceride concentration in Sf $>400$ lipoproteins was markedly elevated in the HTG group compared with the control and NTG patient groups and had increased even further at $6 \mathrm{~h}$, whereas the level was unchanged between 3 and $6 \mathrm{~h}$ in the NTG group and re- 
Table II. Fasting Plasma Concentrations of Cholesterol, Triglycerides, and Apolipoprotein B in Triglyceride-rich Lipoproteins and of Cholesterol and Triglycerides in Low Density Lipoproteins and High Density Lipoproteins

\begin{tabular}{lccc}
\hline & $\begin{array}{c}\text { Controls } \\
n=10\end{array}$ & $\begin{array}{c}\text { NTG patients } \\
n=17\end{array}$ & $\begin{array}{c}\text { HTG patients } \\
n=15\end{array}$ \\
\hline TGRL fraction & & & \\
Sf 60-400 & & & \\
Chol (mmol/liter) & $0.06 \pm 0.05$ & $0.09 \pm 0.07$ & $0.46 \pm 0.32^{*}$ \\
TG (mmol/liter) & $0.37 \pm 0.18$ & $0.48 \pm 0.26$ & $1.67 \pm 1.14^{*}$ \\
Apo B-100 (mg/liter) & $36 \pm 31$ & $43 \pm 34$ & $89 \pm 59^{\ddagger \S}$ \\
Apo B-48 (mg/liter) & $2 \pm 2$ & $2 \pm 3$ & $8 \pm 6^{\| 1}$ \\
Sf 20-60 & & & \\
Chol (mmol/liter) & $0.21 \pm 0.17$ & $0.18 \pm 0.10$ & $0.56 \pm 0.33^{*}$ \\
TG (mmol/liter) & $0.28 \pm 0.14$ & $0.33 \pm 0.19$ & $0.74 \pm 0.52^{\S ! 1}$ \\
Apo B-100 (mg/liter) & $42 \pm 41$ & $41 \pm 27$ & $77 \pm 42^{\ddagger}$ \\
Apo B-48 (mg/liter) & $3 \pm 3$ & $3 \pm 3$ & $8 \pm 4^{\S 1}$ \\
Sf 12-20 & & & \\
Chol (mmol/liter) & $0.28 \pm 0.14$ & $0.28 \pm 0.13$ & $0.43 \pm 0.11^{\| 1}$ \\
TG (mmol/liter) & $0.09 \pm 0.03$ & $0.12 \pm 0.04$ & $0.14 \pm 0.09$ \\
Apo B-100 (mg/liter) & $53 \pm 18$ & $49 \pm 28$ & $52 \pm 20$ \\
Apo B-48 (mg/liter) & $1 \pm 2$ & $1 \pm 1$ & $2 \pm 3$ \\
LDL & & & \\
Chol (mmol/liter) & $4.06 \pm 0.61$ & $4.56 \pm 0.84$ & $4.22 \pm 0.71$ \\
TG (mmol/liter) & $0.37 \pm 0.08$ & $0.46 \pm 0.13$ & $0.42 \pm 0.07$ \\
HDL & & & \\
Chol (mmol/liter) & $1.38 \pm 0.36$ & $1.08 \pm 0.35^{\S}$ & $0.86 \pm 0.14^{* *}$ \\
TG (mmol/liter) & $0.11 \pm 0.05$ & $0.12 \pm 0.05$ & $0.14 \pm 0.04$ \\
\hline & & & \\
\hline & & & \\
\hline & & & \\
\hline
\end{tabular}

Values are mean $\pm \mathrm{SD}$. Chol, cholesterol; TG, triglycerides. Analysis of variance: The Scheffe F-test was used to identify differences among the groups when the overall $F$ statistic was significant.

${ }^{*} P<0.001$ compared with both controls and NTG patients; ${ }^{\ddagger} P$ $<0.05$ compared with NTG patients; ${ }^{\S} P<0.05$ compared with controls; " $P<0.01$ compared with controls; ' $P<0.01$ compared with NTG patients; ${ }^{* *} P<0.001$ compared with controls.

duced at $6 \mathrm{~h}$ in the control group. Base line levels were attained in all groups $12 \mathrm{~h}$ after the fat load.

The pattern of triglyceride elevation induced by the oral fat load in the Sf 60-400 lipoprotein fraction was similar to the $\mathrm{Sf}$ $>400$ lipoprotein fraction. The triglyceride concentrations in the 3-and 6-h plasma samples were two to three times higher in the HTG group than in either controls or the NTG patients. The Sf $60-400$ apo B-48 concentration of the HTG patients increased to twice that in the control group at $3 \mathrm{~h}$. The peak of apo B-48 appeared to be around $3 \mathrm{~h}$ in the control group, between 3 and $6 \mathrm{~h}$ in the NTG patient group, and around $6 \mathrm{~h}$ in the HTG patient group. Thus, the response of apo B- 48 was both prolonged and exaggerated in the HTG patient group. The apo B-100 concentration almost doubled between the fasting and the 3-h sample in all groups and remained at this level at $6 \mathrm{~h}$ in both the NTG and the HTG patient groups, whereas a reduction was seen in the control group. Base line, or even lower than base line levels, were attained at $12 \mathrm{~h}$ in all groups.

The triglyceride concentration of the $\mathrm{Sf} 20-60$ fraction was not influenced by the oral fat load in any of the study groups. A statistically significant rise in apo B-48 was seen at $3 \mathrm{~h}$ in the control group and both at 3 and $6 \mathrm{~h}$ in the NTG patient group.
In contrast, there was no increase in apo B- 48 by the oral fat load in the HTG subjects, in whom the apo B-48 concentration was significantly elevated already in the fasting plasma sample. Concerning the apo B-100 response in the Sf 20-60 fraction, the postprandial level was unchanged in the control and NTG patient groups, whereas a reduction was seen $3 \mathrm{~h}$ after intake of the oral fat load in the HTG patient group. The base line level was attained at $12 \mathrm{~h}$ in the HTG group.

The triglyceride and apo B-48 concentrations in the Sf 12 20 fraction remained unchanged throughout the test in all groups, whereas a significant reduction of apo B-100 was seen at $3 \mathrm{~h}$ in the control group and at both 3 and $6 \mathrm{~h}$ in the NTG and HTG patient groups.

Apo C-I, C-II, C-III, and E in whole plasma during the oral fat tolerance test. The whole plasma concentrations of apo C-I, C-II, C-III, and E in fasting samples and after intake of the oral fat load are shown in Table IV. For the concentrations of apo C-I, there were no statistically significant differences between the groups at any time point. The levels were essentially unchanged at 3 and $6 \mathrm{~h}$ after intake of the oral fat load, whereas a consistent decrease of $\sim 15 \%$ was seen at $12 \mathrm{~h}$ in all groups. The fasting plasma concentrations of apo C-II and C-III were highest in the HTG group. No major changes were seen at 3 and $6 \mathrm{~h}$ in either patients or controls, while a decrease ranging between 10 and $30 \%$ was found at $12 \mathrm{~h}$ in all groups. For apo E, similar to apo C-I, C-II, and C-III, the fasting plasma concentration was increased in the HTG group and a decrease was observed at $12 \mathrm{~h}$ in all groups.

Apo C-I, C-II, C-III, and E in triglyceride-rich lipoproteins during the oral fat tolerance test. Plasma concentrations of apo C-I, C-II, C-III, and E in TGRL in fasting samples and after intake of the oral fat load are shown in Table V. In fasting samples the HTG group had elevated levels of apo C-I, C-II, $\mathrm{C}$-III, and $\mathrm{E}$ in the $\mathrm{Sf} 60-400$ and Sf $20-60$ fractions. The ratios of apo Cs and E to apo B (apo B-48 + apo B-100) were elevated in the Sf $60-400$ fraction of the HTG patients compared to both NTG patients and controls (Tables III and V). In contrast, the corresponding ratios were similar for the Sf 20-60 fraction in all groups. Only trace amounts were found in the Sf $>400$ fraction of fasting samples and low levels, occasionally close to the limit of quantification, were measured in postprandial samples of this fraction. In the Sf 60-400 lipoprotein fraction major elevations of apo C-I and $E$ were induced by the oral fat load in all groups. The relative increments of apo C-I and E resembled those of apo B-48, apo B-100, and triglycerides in this fraction. The levels of apo C-II and apo C-III in the control group were doubled at $3 \mathrm{~h}$, subsequently reduced at $6 \mathrm{~h}$, and reached base line level at $12 \mathrm{~h}$. In the NTG patient group, the levels of apo C-II and apo C-III were increased at both 3 and 6 $\mathrm{h}$, in parallel with the apo B-48, apo B-100, and triglyceride concentrations. In contrast, there was no significant postprandial increment of the mean apo C-II level in the Sf $60-400$ fraction among HTG patients. An insignificant increase of apo $\mathrm{C}$-III was seen at $3 \mathrm{~h}$ in these subjects.

The oral fat load failed to induce changes in the concentrations of apo C-I, C-II, C-III, or E in the Sf 20-60 lipoprotein fraction in either the controls or the NTG patients. Decreases by $\sim 50 \%$ of apo C-II and C-III were found at both 3 and $6 \mathrm{~h}$ in the HTG patient group.

The relative changes in triglycerides, apo C-II, and the sum of apo B-48 and apo B-100 in the Sf 60-400 fraction in the three groups are shown in Fig. 2. In the controls and the NTG 
Table III. Concentration of Triglycerides in the $S f>400$ Fraction and of Triglycerides, apo B-100, and apo B-48 in the Sf 60-400, Sf 20-60, and Sf 12-20 Fractions during the Oral Fat Tolerance Test

\begin{tabular}{|c|c|c|c|c|c|c|c|c|c|c|}
\hline & \multirow{2}{*}{$\frac{\mathrm{Sf}>\mathbf{4 0 0}}{\mathrm{TG}}$} & \multicolumn{3}{|c|}{ Sf $60-400$} & \multicolumn{3}{|c|}{ Sf $20-60$} & \multicolumn{3}{|c|}{ Sf $12-20$} \\
\hline & & TG & Apo B-48 & Apo B-100 & TG & Apo B-48 & Apo B-100 & TG & Apo B-48 & Apo B-100 \\
\hline & $\mathrm{mmol} / \mathrm{liter}$ & $\mathrm{mmol} / \mathrm{liter}$ & \multicolumn{2}{|c|}{ mg/liter } & $\mathrm{mmol} / \mathrm{liter}$ & \multicolumn{2}{|c|}{$m g / l i t e r$} & $\mathrm{mmol} / \mathrm{liter}$ & \multicolumn{2}{|c|}{$m g / l i t e r$} \\
\hline \multicolumn{11}{|c|}{$\begin{array}{l}\text { Controls } \\
\qquad n=10\end{array}$} \\
\hline $\mathrm{Oh}$ & $0.02 \pm 0.02$ & $0.37 \pm 0.18$ & $2 \pm 2$ & $36 \pm 31$ & $0.28 \pm 0.14$ & $3 \pm 3$ & $42 \pm 41$ & $0.09 \pm 0.03$ & $1 \pm 2$ & $53 \pm 18$ \\
\hline \multirow[t]{2}{*}{$3 \mathrm{~h}$} & $0.82 \pm 0.37$ & $1.05 \pm 0.42$ & $15 \pm 9$ & $73 \pm 41$ & $0.31 \pm 0.12$ & $6 \pm 2$ & $39 \pm 33$ & $0.08 \pm 0.02$ & $1 \pm 2$ & $42 \pm 13$ \\
\hline & $P<0.001$ & $P<0.001$ & $P<0.001$ & $P<0.001$ & NS & $P<0.05$ & NS & NS & NS & $P<0.05$ \\
\hline \multirow[t]{2}{*}{$6 \mathrm{~h}$} & $0.37 \pm 0.18$ & $0.75 \pm 0.45$ & $9 \pm 7$ & $48 \pm 44$ & $0.28 \pm 0.13$ & $4 \pm 4$ & $39 \pm 33$ & $0.08 \pm 0.03$ & $1 \pm 2$ & $47 \pm 14$ \\
\hline & $P<0.001$ & $P<0.01$ & $P<0.01$ & NS & NS & NS & NS & NS & NS & NS \\
\hline \multirow[t]{2}{*}{$12 \mathrm{~h}$} & $0.02 \pm 0.02$ & $0.22 \pm 0.12$ & 0 & $22 \pm 23$ & $0.16 \pm 0.11$ & $1 \pm 2$ & $41 \pm 39$ & $0.07 \pm 0.03$ & $1 \pm 1$ & $47 \pm 20$ \\
\hline & NS & $P<0.01$ & & NS & $P<0.01$ & $P<0.05$ & NS & NS & NS & NS \\
\hline \multicolumn{11}{|c|}{$\begin{array}{c}\text { NTG patients } \\
n=17\end{array}$} \\
\hline $\mathrm{Oh}$ & $0.01 \pm 0.01$ & $0.48 \pm 0.26$ & $2 \pm 3$ & $43 \pm 34$ & $0.33 \pm 0.19$ & $3 \pm 3$ & $41 \pm 27$ & $0.12 \pm 0.04$ & $1 \pm 1$ & $49 \pm 28$ \\
\hline \multirow[t]{2}{*}{$3 \mathrm{~h}$} & $0.71 \pm 0.41$ & $1.16 \pm 0.66$ & $20 \pm 12$ & $80 \pm 58$ & $0.33 \pm 0.17$ & $8 \pm 5$ & $43 \pm 25$ & $0.10 \pm 0.03$ & $1 \pm 1$ & $40 \pm 20$ \\
\hline & $P<0.001$ & $P<0.001$ & $P<0.001$ & $P<0.01$ & NS & $P<0.001$ & NS & $P<0.01$ & NS & $P<0.01$ \\
\hline \multirow[t]{2}{*}{$6 \mathrm{~h}$} & $0.68 \pm 0.41$ & $1.21 \pm 0.68$ & $21 \pm 17$ & $87 \pm 57$ & $0.32 \pm 0.11$ & $5 \pm 4$ & $44 \pm 19$ & $0.10 \pm 0.03$ & $1 \pm 1$ & $40 \pm 20$ \\
\hline & $P<0.001$ & $P<0.001$ & $P<0.001$ & $P<0.001$ & NS & $P<0.05$ & NS & NS & NS & $P<0.05$ \\
\hline \multirow[t]{2}{*}{$12 \mathrm{~h}$} & $0.06 \pm 0.11$ & $0.30 \pm 0.21$ & $2 \pm 3$ & $20 \pm 17$ & $0.20 \pm 0.12$ & $2 \pm 2$ & $31 \pm 23^{\prime \prime}$ & $0.11 \pm 0.03$ & $1 \pm 1$ & $44 \pm 27$ \\
\hline & NS & $P<0.01$ & NS & $P<0.05$ & $P<0.05$ & NS & NS & NS & NS & $P<0.05$ \\
\hline \multicolumn{11}{|c|}{$\begin{array}{c}\text { HTG patients } \\
n=15\end{array}$} \\
\hline $0 \mathrm{~h}$ & $0.08 \pm 0.09$ & $1.67 \pm 1.14^{*}$ & $8 \pm 6^{\ddagger 5}$ & $89 \pm 59^{111}$ & $0.74 \pm 0.52^{\ddagger 5}$ & $8 \pm 4^{115}$ & $77 \pm 42^{\prime}$ & $0.14 \pm 0.09$ & $2 \pm 3$ & $52 \pm 20$ \\
\hline \multirow[t]{2}{*}{$3 \mathrm{~h}$} & $1.81 \pm 0.71^{*}$ & $2.67 \pm 1.00^{*}$ & $29 \pm 13^{11}$ & $170 \pm 47^{*}$ & $0.72 \pm 0.76$ & $8 \pm 4$ & $55 \pm 31$ & $0.13 \pm 0.08$ & $2 \pm 2$ & $43 \pm 22$ \\
\hline & $P<0.001$ & $P<0.001$ & $P<0.001$ & $P<0.001$ & NS & NS & $P<0.01$ & NS & NS & $P<0.05$ \\
\hline \multirow[t]{2}{*}{$6 \mathrm{~h}$} & $2.24 \pm 1.23^{*}$ & $3.17 \pm 1.41^{*}$ & $37 \pm 18^{* * 1}$ & $164 \pm 48^{*}$ & $0.60 \pm 0.31^{*}$ & $8 \pm 6$ & $66 \pm 29$ & $0.10 \pm 0.06$ & $2 \pm 2$ & $35 \pm 15$ \\
\hline & $P<0.001$ & $P<0.001$ & $P<0.001$ & $P<0.001$ & NS & NS & NS & NS & NS & $P<0.001$ \\
\hline \multirow[t]{2}{*}{$12 \mathrm{~h}$} & $0.16 \pm 0.22$ & $1.31 \pm 1.38^{\neq 5}$ & $9 \pm 11^{\prime}$ & $77 \pm 58^{84}$ & $0.54 \pm 0.34^{*}$ & $6 \pm 7^{111}$ & $70 \pm 37^{8}$ & $0.13 \pm 0.05^{\ddagger}$ & $2 \pm 3$ & $54 \pm 32$ \\
\hline & NS & NS & NS & NS & NS & NS & NS & NS & NS & NS \\
\hline
\end{tabular}

Values are mean \pm SD.

TG, triglycerides; $h$, hours after intake of the oral fat load. Analysis of variance: The Scheffe F-test was used to identify differences among the groups when the overall F statistic was significant. The statistical significance of differences between 0 and 3, 6, and 12-h determinations in each group was calculated by Student's paired $t$ test and given directly below the postprandial time points.

* $P<0.001$ compared with both control and NTG patients; ${ }^{\ddagger} P<0.01$ compared with controls; $\$ P<0.01$ compared with NTG patients; $P<0.05$ compared with controls; ' $P<0.05$ compared with NTG patients; $* * P<0.001$ compared with controls.

patient group, the response of lipid and apoprotein parameters to the oral fat load were parallel. Of note, the relative amount of apo C-II was unchanged in the Sf 60-400 fraction in the HTG patient group despite unequivocally increased postprandial apo $B$ and triglyceride levels in this fraction.

Influence of apo E genotype on responses to the oral fat load. Fasting and postprandial levels of triglycerides, apo B-48, and apo B-100 in the Sf 60-400 and Sf 20-60 fractions were compared among the 7 subjects who were heterozygous for the apo E2 allele and the 35 subjects who were either E4/E4, E4/E3, or E3/E3. With due regard to the limited number of subjects with an E2 allele, no significant differences were recorded between the groups. Within group comparison between various time points also revealed similar patterns in the groups, except for apo B-100 in the Sf 20-60 fraction. In subjects with an E2 allele, fasting and 12-h levels were similar, whereas the 12-h apo B-100 values were significantly lower than base line in the group without an E2 allele.

Relations of postheparin plasma LPL and HL activity levels to responses to the oral fat load. Relations of postheparin plasma LPL and HL activity levels to postprandial lipoproteins are shown in Table VI. The magnitude of the postprandial responses of TGRL to the oral fat load was calculated as the AUC for plasma measurements of apo B-48 and apo B-100 in the Sf $60-400$ and Sf 20-60 fractions throughout the test. The AUCs for apo B-48 and apo B-100 in Sf 60-400 lipoproteins showed weak negative correlations to LPL when all subjects were analyzed together. However, no significant relations were found in any of the three groups when each was analyzed separately. It should be noted that the HTG subjects generally had a lower LPL level and a higher AUC for apo B-48 in the Sf 60400 fraction than either NTG patients or control subjects. A similar pattern was found for triglycerides (data not shown).

For HL, significant positive correlations were found between HL and the AUCs for apo B-48 and apo B-100 in the Sf 60-400 lipoprotein fraction. HL correlated positively with the AUC for Sf 20-60 apo B-48 in the NTG group and with the AUC for Sf 20-60 apo B-100 in all subjects taken together. These associations should be interpreted with due caution as in the case of LPL, since the mean levels of HL varied between the groups.

\section{Discussion}

The present study dealt with the metabolism of TGRL after ingestion of a fat meal in healthy controls and NTG and HTG patients with manifest CAD. Differentiation of postprandial gut-derived TGRL from hepatogenous TGRL can be achieved 

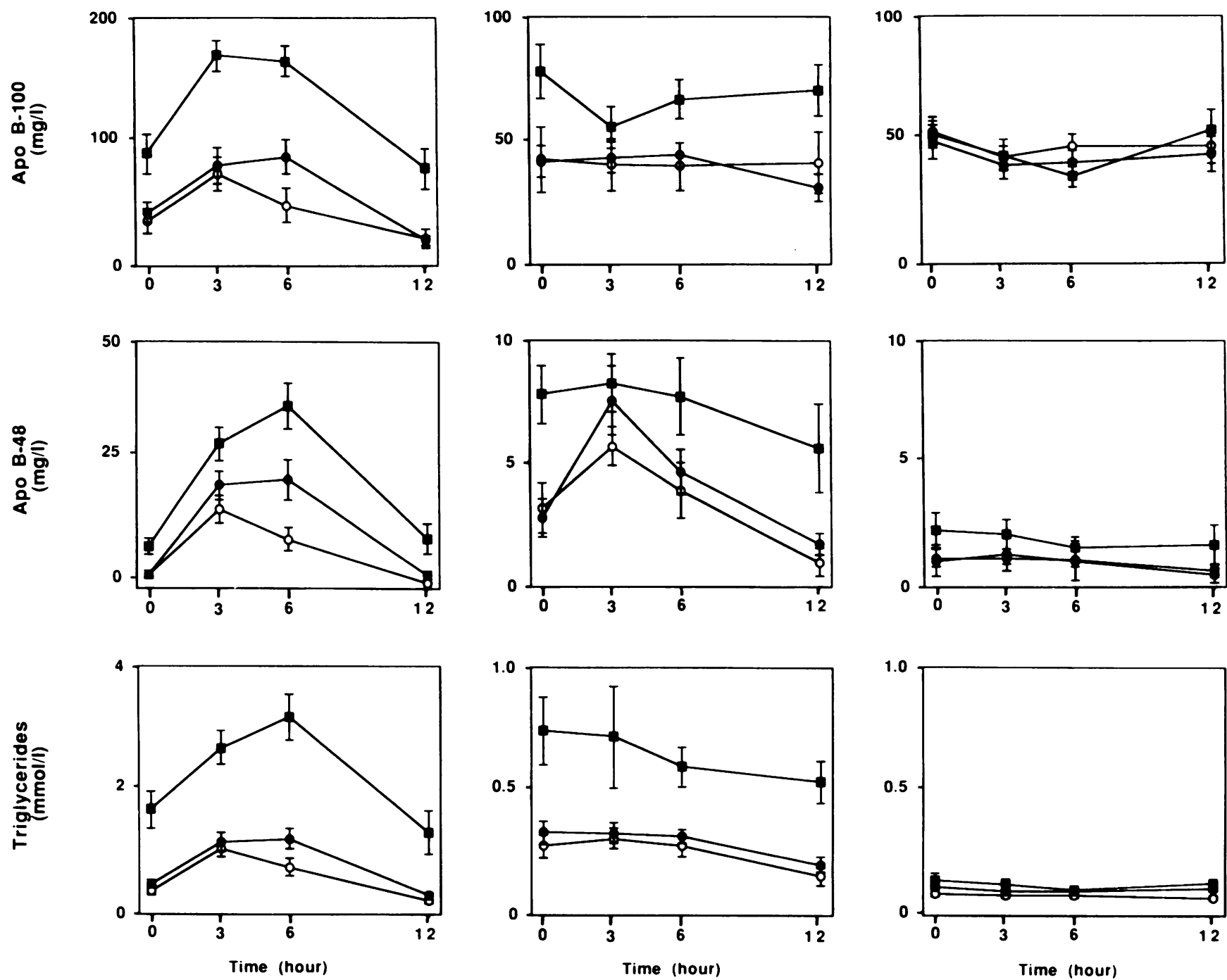

Figure 1. Line plots of apo B-100, apo B-48, and triglycerides after ingestion of the oral fat load in Sf 60-400, Sf 20-60, and Sf 12-20 lipoprotein fractions. Values are mean \pm SEM, with SEM indicated by bars. $O$, Control subjects; $\bullet$, normotriglyceridemic patients; and $\bullet$, hypertriglyceridemic patients.

in two ways. Either the chylomicron fraction is labeled with orally administered vitamin A and chylomicrons and chylomicron remnants subsequently quantified by measurement of plasma retinyl esters, or specific determination of apo B-48 in plasma is used. Several studies have used the retinyl palmitate method which has been shown to provide reliable measures of chylomicrons and chylomicron remnants. With the use of this method delayed clearance of chylomicron remnants has been demonstrated in dyslipidemic (12) and hyperlipidemic subjects $(18,41)$, and in patients with CAD and no lipoprotein abnormalities (19).

To the best of our knowledge direct quantification of apo B-48 and apo B-100 in subfractions of postprandial TGRL has not been performed previously. Our data suggest that chylomicron remnants appear in plasma soon after intake of an oral fat load. All apo B-48-containing lipoproteins in the Sf 60-400 fraction are not necessarily chylomicron remnants, since secretion of chylomicrons into this fraction cannot be entirely ruled out. However, in this work chylomicron remnants and Sf 60 400 lipoproteins containing apo B-48 were equated. In NTG subjects, increases in the concentrations of both large ( $\mathrm{Sf}$ 60400 ) and small (Sf 20-60) chylomicron remnants occurred in response to the oral fat load. In contrast, the HTG patients responded with increased plasma levels of large chylomicron remnants only, whereas no change was seen in the small chylomicron remnant fraction, which in this group was clearly elevated already in the fasting state. This implies a profound defect in the metabolism of chylomicron remnants in hypertriglyceridemia. Turnover studies of VLDL have shown that HTG VLDL to a large extent is cleared from the circulation as large VLDL (42). Our findings suggest that this may also be true for large chylomicron remnants.

The increase of large chylomicron remnants was accompanied by elevation of large (Sf 60-400) VLDL in all study groups, with reduced concentrations of apo B-100 in Sf 12-60 lipoproteins. The peak plasma level of the large VLDL seemed 
Table IV. Concentrations of Apolipoproteins C-I, C-II, C-III, and $E$ in Whole Plasma during the Oral Fat Tolerance Test

\begin{tabular}{|c|c|c|c|c|}
\hline & Apo C-I & Apo C-II & Apo C-III & Apo E \\
\hline & \multicolumn{4}{|c|}{$\mathrm{mg} / \mathrm{liter}$} \\
\hline \multicolumn{5}{|c|}{$n=10$} \\
\hline $0 \mathrm{~h}$ & $131 \pm 43$ & $88 \pm 22$ & $157 \pm 37$ & $40 \pm 15$ \\
\hline $3 \mathrm{~h}$ & $\begin{array}{c}127 \pm 37 \\
\text { NS }\end{array}$ & $\begin{array}{l}94 \pm 25 \\
\text { NS }\end{array}$ & $\begin{array}{c}146 \pm 30 \\
\text { NS }\end{array}$ & $\begin{array}{c}40 \pm 15 \\
\text { NS }\end{array}$ \\
\hline $6 \mathrm{~h}$ & $\begin{array}{c}115 \pm 27 \\
\text { NS }\end{array}$ & $\begin{array}{c}86 \pm 29 \\
\text { NS }\end{array}$ & $\begin{array}{r}127 \pm 30 \\
P<0.01\end{array}$ & $\begin{array}{c}40 \pm 13 \\
\text { NS }\end{array}$ \\
\hline $12 \mathrm{~h}$ & $\begin{array}{c}108 \pm 29 \\
P<0.01\end{array}$ & $\begin{array}{c}70 \pm 22 \\
P<0.001\end{array}$ & $\begin{array}{c}110 \pm 20 \\
P<0.001\end{array}$ & $\begin{array}{c}31 \pm 11 \\
P<0.01\end{array}$ \\
\hline \multicolumn{5}{|c|}{$\begin{array}{c}\text { NTG patients } \\
n=17\end{array}$} \\
\hline $0 \mathrm{~h}$ & $114 \pm 34$ & $68 \pm 20$ & $114 \pm 42$ & $43 \pm 10$ \\
\hline $3 \mathrm{~h}$ & $\begin{array}{c}104 \pm 26 \\
P<0.01\end{array}$ & $\begin{array}{c}74 \pm 23 \\
\text { NS }\end{array}$ & $\begin{array}{r}103 \pm 42 \\
P<0.05\end{array}$ & $\begin{array}{c}39 \pm 7 \\
P<0.05\end{array}$ \\
\hline $6 \mathrm{~h}$ & $\begin{array}{c}109 \pm 34 \\
\text { NS }\end{array}$ & $\begin{array}{l}71 \pm 21 \\
\text { NS }\end{array}$ & $\begin{array}{c}107 \pm 45 \\
\text { NS }\end{array}$ & $\begin{array}{c}40 \pm 10 \\
\text { NS }\end{array}$ \\
\hline $12 \mathrm{~h}$ & $\begin{array}{c}100 \pm 27 \\
P<0.05\end{array}$ & $\begin{array}{r}59 \pm 18 \\
P<0.05\end{array}$ & $\begin{array}{c}85 \pm 32 \\
P<0.001\end{array}$ & $\begin{array}{c}33 \pm 8 \\
P<0.001\end{array}$ \\
\hline \multicolumn{5}{|c|}{$\begin{array}{c}\text { HTG patients } \\
\quad n=15\end{array}$} \\
\hline $0 \mathrm{~h}$ & $148 \pm 35$ & $108 \pm 22^{\ddagger}$ & $182 \pm 56^{\S}$ & $56 \pm 10^{* \delta}$ \\
\hline \multirow[t]{2}{*}{$3 \mathrm{~h}$} & $139 \pm 35$ & $109 \pm 21^{\ddagger}$ & $162 \pm 51^{\S}$ & $53 \pm 12^{\S}$ \\
\hline & $P<0.05$ & NS & $P<0.001$ & $P<0.05$ \\
\hline $6 \mathrm{~h}$ & $\begin{array}{c}144 \pm 42 \\
\text { NS }\end{array}$ & $\begin{array}{c}107 \pm 24^{\ddagger} \\
\text { NS }\end{array}$ & $\begin{array}{c}175 \pm 41^{\ddagger} \\
\text { NS }\end{array}$ & $\begin{array}{c}53 \pm 10^{\S} \\
\text { NS }\end{array}$ \\
\hline $12 \mathrm{~h}$ & $\begin{array}{l}133 \pm 39 \\
P<0.05\end{array}$ & $\begin{array}{c}98 \pm 27^{\ddagger} \\
P<0.01\end{array}$ & $\begin{array}{l}153 \pm 42^{\ddagger} \\
P<0.01\end{array}$ & $\begin{array}{l}46 \pm 11^{\S} \\
P<0.01\end{array}$ \\
\hline
\end{tabular}

Values are mean $\pm S D$. Analysis of variance: The Scheffe $F$ test was used to identify differences among the groups when the overall $F$ statistic was significant. The statistical significance of differences between $0 \mathrm{~h}$ and 3, 6, and $12 \mathrm{~h}$ determinations in each group was calculated by Student's paired $t$ test and given directly below the postprandial time points.

${ }^{*} P<0.01$ compared with controls; ${ }^{\ddagger} P<0.001$ compared with NTG patients; ${ }^{\S} P<0.01$ compared with NTG patients.

to coincide with that for large chylomicron remnants. The explanation for the VLDL elevation is not obvious. Both an increased postprandial synthesis of apo B-100, increased assembly of VLDL and a reduced rate of degradation have to be considered. On the one hand, the early postprandial state most probably does not involve any substantial mobilization of substrate for increased hepatic VLDL production from adipose tissue. However, from a theoretical point of view, the glucose content of the mixed meal could provide substrate for hepatic triglyceride production. Furthermore, remnants of TGRL accumulating in postprandial plasma may be rapidly taken up by the liver and in this way provide the lipid substrate for increased VLDL production. Most likely, the VLDL production that may be induced by these two events should be delayed compared to the generation of chylomicrons. Since the rise of Sf $60-400$ apo B-100 was seen almost simultaneously with the increase of Sf 60-400 apo B-48 we suggest that increased syn- thesis of VLDL contributes to the accumulation of postprandial VLDL only to a limited extent. This line of reasoning also presupposes that the intestinal apo B-100 production is negligible. On the other hand, it is generally accepted that the removal of triglycerides from chylomicrons and VLDL is achieved by the same enzymatic pathway (43). Therefore, the lipolysis of VLDL might be influenced by the appearance in plasma of newly synthesized chylomicrons during alimentary lipemia. Impeded degradation of VLDL due to this substrate competion could thus also explain the increased postprandial levels of large VLDL. A concomitant decrease of small VLDL would then be anticipated due to slow degradation of the larger VLDL particles. The reduced plasma concentrations of apo B-100 in the Sf 20-60 fraction in the HTG subjects and in the Sf 12-20 fraction in all study groups support the notion of delayed degradation of VLDL during alimentary lipemia. However, the data should be interpreted with due caution since neither the rates of conversion nor the rates of clearance of apo B-100 in TGRL and their dependence on plasma levels were actually measured.

A massive increase of apo B-48 and a limited increase of apo B-100 in the TGRL fraction has been demonstrated previously in healthy subjects by Cohn et al. (22), who concluded that both the liver and the intestine contribute to postprandial triglyceridemia. However, in their study the total TGRL fraction was delipidated and separation of apolipoproteins was performed with SDS-PAGE. The increases of apo B-48 and B-100 were expressed in relation to the fasting levels. Cohn et al. subsequently studied the effect of fasted and fed conditions on the synthetic rate of VLDL apo B-100 using a sensitive isotope dilution technique (44). They concluded that the synthesis of VLDL apo B-100 increased by $\sim 50 \%$ in fed compared with fasted individuals. However, the possible effect of competition in the lipolytic system between newly synthesized chylomicrons and VLDL was not taken into account in their analysis.

An alternative hypothesis to explain the VLDL elevation during alimentary lipemia should also be pointed out. In tracer studies of TGRL it is often seen that the plasma volume upon reinjection of radioiodinated VLDL is smaller than the initial plasma volume calculated by an isotope dilution technique (45). One reason for this phenomenon might be that TGRL undergoing lipolysis are attached to LPL bound to the endothelium and are not evenly distributed in plasma. If a better substrate for LPL appears, then the previously bound TGRL are released with a subsequent increase in plasma concentration. Generation of chylomicrons and chylomicron remnants can thus hypothetically reduce the "margination" of VLDL.

The fasting plasma levels of cholesterol in the Sf 60-400, Sf 20-60, and Sf 12-20 fractions were increased in the HTG patients, and on a per particle basis, the cholesterol content was clearly elevated in these fractions in the HTG subjects. This finding has been documented in previous studies (46). Since chylomicron remnants and VLDL particles were not isolated, no valid assessment of particle composition could be made on postprandial plasma samples.

Degradation of TGRL triglycerides is catalyzed by LPL. However, no consistent associations were observed between postheparin LPL activity and the AUCs for apo B-48 or apo B-100 in the Sf $60-400$ fraction taken as a measure of the postprandial levels of large chylomicron remnants and large VLDL particles, respectively. This is in agreement with the observations by Weintraub et al. (16). Although they found negative correlations between the postheparin plasma LPL ac- 
Table V. Concentrations of Apolipoproteins C-I, C-II, C-III, and E during the Oral Fat Tolerance Test in the Sf>400, Sf 60-400, and Sf 20-60 Lipoprotein Fractions

\begin{tabular}{|c|c|c|c|c|c|c|c|c|c|c|c|c|}
\hline & \multicolumn{4}{|c|}{$\mathrm{Sf}>400$} & \multicolumn{4}{|c|}{ Sf $60-400$} & \multicolumn{4}{|c|}{ Sf $20-60$} \\
\hline & Apo C-I & Apo C-II & Apo C-III & Apo E & Apo C-I & Apo C-II & Apo C-III & Apo E & Apo C-I & Apo C-II & Apo C-III & Apo E \\
\hline & \multicolumn{4}{|c|}{$m g / l i t e r$} & \multicolumn{4}{|c|}{$m g / l i t e r$} & \multicolumn{4}{|c|}{$m g / l i t e r$} \\
\hline \multicolumn{13}{|c|}{$\begin{array}{l}\text { Controls } \\
\qquad n=10\end{array}$} \\
\hline $0 \mathrm{~h}$ & $\mathrm{~T}$ & $\mathrm{~T}$ & $\mathrm{~T}$ & $\mathrm{~T}$ & $2 \pm 1$ & $13 \pm 17$ & $14 \pm 8$ & $1 \pm 1$ & $3 \pm 2$ & $9 \pm 7$ & $13 \pm 6$ & $3 \pm 3$ \\
\hline \multirow[t]{2}{*}{$3 \mathrm{~h}$} & $1 \pm 1$ & $2 \pm 1$ & $6 \pm 3$ & $1 \pm 1$ & $11 \pm 12$ & $24 \pm 12$ & $39 \pm 21$ & $3 \pm 2$ & $4 \pm 2$ & $8 \pm 5$ & $11 \pm 8$ & $3 \pm 3$ \\
\hline & & & & & $P<0.05$ & $P<0.01$ & $P<0.01$ & $P<0.01$ & NS & NS & NS & NS \\
\hline \multirow[t]{2}{*}{$6 \mathrm{~h}$} & $1 \pm 1$ & $1 \pm 1$ & $2 \pm 2$ & $T$ & $7 \pm 6$ & $19 \pm 18$ & $22 \pm 23$ & $4 \pm 3$ & $5 \pm 3$ & $8 \pm 5$ & $12 \pm 8$ & $3 \pm 3$ \\
\hline & & & & & $P<0.05$ & NS & NS & $P<0.05$ & NS & NS & NS & NS \\
\hline \multirow[t]{2}{*}{$12 \mathrm{~h}$} & $\mathrm{~T}$ & $\mathrm{~T}$ & $\mathrm{~T}$ & $\mathrm{~T}$ & $2 \pm 1$ & $8 \pm 7$ & $9 \pm 7$ & $1 \pm 1$ & $3 \pm 2$ & $9 \pm 15$ & $9 \pm 8$ & $2 \pm 3$ \\
\hline & & & & & NS & NS & NS & NS & NS & NS & NS & NS \\
\hline \multicolumn{13}{|c|}{$\begin{array}{c}\text { NTG patients } \\
n=17\end{array}$} \\
\hline $0 \mathrm{~h}$ & $\mathrm{~T}$ & $\mathrm{~T}$ & $\mathrm{~T}$ & $\mathrm{~T}$ & $4 \pm 2$ & $14 \pm 10$ & $18 \pm 12$ & $1 \pm 1$ & $5 \pm 2$ & $7 \pm 3$ & $14 \pm 8$ & $3 \pm 2$ \\
\hline \multirow[t]{2}{*}{$3 \mathrm{~h}$} & $1 \pm 1$ & $5 \pm 12$ & $5 \pm 4$ & $1 \pm 1$ & $8 \pm 4$ & $25 \pm 22$ & $34 \pm 26$ & $5 \pm 4$ & $5 \pm 2$ & $9 \pm 5$ & $13 \pm 9$ & $3 \pm 2$ \\
\hline & & & & & $P<0.001$ & $P<0.05$ & $P<0.01$ & $P<0.01$ & NS & NS & NS & NS \\
\hline \multirow[t]{2}{*}{$6 \mathrm{~h}$} & $2 \pm 1$ & $6 \pm 12$ & $7 \pm 8$ & $1 \pm 1$ & $11 \pm 7$ & $31 \pm 31$ & $38 \pm 33$ & $8 \pm 8$ & $6 \pm 3$ & $10 \pm 9$ & $14 \pm 10$ & $3 \pm 2$ \\
\hline & & & & & $P<0.001$ & $P<0.05$ & $P<0.01$ & $P<0.01$ & NS & NS & NS & NS \\
\hline \multirow[t]{2}{*}{$12 \mathrm{~h}$} & $\mathrm{~T}$ & $\mathrm{~T}$ & $\mathrm{~T}$ & $\mathrm{~T}$ & $3 \pm 2$ & $10 \pm 7$ & $14 \pm 11$ & $1 \pm 1$ & $3 \pm 2$ & $8 \pm 6$ & $11 \pm 11$ & $4 \pm 2$ \\
\hline & & & & & NS & NS & $P<0.05$ & NS & $P<0.01$ & NS & NS & NS \\
\hline \multicolumn{13}{|c|}{ HTG patients } \\
\hline $0 \mathrm{~h}$ & $\mathrm{~T}$ & $T$ & $\mathrm{~T}$ & $\mathrm{~T}$ & $14 \pm 10$ & $57 \pm 36^{811}$ & $43 \pm 36^{* \ddagger}$ & $5 \pm 4^{\S \|}$ & $11 \pm 12$ & $21 \pm 15^{* \|}$ & $21 \pm 13$ & $7 \pm 6$ \\
\hline \multirow[t]{2}{*}{$3 \mathrm{~h}$} & $3 \pm 3^{* \pm}$ & $6 \pm 5$ & $9 \pm 7$ & $1 \pm 1$ & $24 \pm 10^{* \|}$ & $58 \pm 22^{\S \|}$ & $55 \pm 49$ & $11 \pm 8^{* \pm}$ & $9 \pm 6^{* \pm}$ & $10 \pm 6$ & $15 \pm 10$ & $7 \pm 5$ \\
\hline & & & & & $P<0.001$ & NS & NS & $P<0.001$ & NS & $P<0.01$ & $P<0.01$ & NS \\
\hline \multirow[t]{2}{*}{$6 \mathrm{~h}$} & $4 \pm 3^{* \pm}$ & $9 \pm 6$ & $11 \pm 10$ & $2 \pm 1$ & $26 \pm 11^{\neq \| 1}$ & $57 \pm 25^{\S \ddagger}$ & $48 \pm 40$ & $17 \pm 10^{\S \|}$ & $9 \pm 4$ & $12 \pm 8$ & $13 \pm 6$ & $6 \pm 5$ \\
\hline & & & & & $P<0.01$ & NS & NS & $P<0.001$ & NS & $P<0.01$ & $P<0.01$ & NS \\
\hline \multirow[t]{2}{*}{$12 \mathrm{~h}$} & $\mathrm{~T}$ & $\mathrm{~T}$ & $\mathrm{~T}$ & $\mathrm{~T}$ & $9 \pm 11$ & $44 \pm 24^{\S ॥}$ & $31 \pm 26^{*}$ & $7 \pm 9$ & $8 \pm 6$ & $19 \pm 12^{\ddagger}$ & $18 \pm 12$ & $6 \pm 5$ \\
\hline & & & & & NS & NS & $P<0.05$ & NS & NS & NS & NS & NS \\
\hline
\end{tabular}

Values are mean \pm SD. T, trace amount. Analysis of variance: The Scheffe $F$ test was used to identify differences among the groups when the overall $\mathrm{F}$ statistic was significant. The statistical significance of differences between $0 \mathrm{~h}$ and 3,6, and $12 \mathrm{~h}$ determinations in each group was calculated by Student's paired $t$ test and given directly below the postprandial time points.

${ }^{*} P<0.01$ compared with controls; ${ }^{\ddagger} P<0.01$ compared with NTG patients; $\$ P<0.001$ compared with controls; $P<0.001$ compared with NTG patients.

tivity and the magnitude of chylomicronemia, no significant correlations were found for LPL and chylomicron remnants. Furthermore, the postheparin LPL activity only gives an estimate of the total amount of LPL attached to the endothelium. Recently Peterson et al. (39) showed that intravenous administration of a lipid emulsion in a dose exceeding the calculated total lipolytic capacity resulted in release of LPL concomitantly with a massive elevation of plasma free fatty acids. It was hypothesized that the rate of lipolysis of TGRL is partly regulated by accumulating free fatty acids which dissociate LPL from its endothelial binding sites. This concept reduces the importance of postheparin LPL measures to determine the capacity for lipolysis of TGRL (47).

We found relatively weak positive associations between the postheparin HL activity and the plasma levels of several postprandial TGRL species. Although HL has been suggested to play a role in the VLDL-intermediate density lipoprotein-LDL conversion cascade (4), its role in chylomicron remnant metab- olism in humans remains obscure. We have recently subjected one of the Swedish HL-deficient patients (48) to the same oral fat tolerance test as described herein. No major disturbances of the metabolism of the postprandial chylomicron remnants were found in this patient (unpublished observation). Because of this and because the correlations between HL activity and the chylomicron remnant responses to the oral fat load were weak, we conclude that HL probably is of minor importance for the human chylomicron remnant metabolism.

The members of the apo $C$ family have been assigned important roles in the metabolism of TGRL. An altered distribution of apo C-II in HTG VLDL was first demonstrated by Kane et al. (49) and later confirmed by others (50). It was found that HTG VLDL had a reduced ratio of apo C-II to total VLDL protein and therefore concluded that this might contribute to the impaired catabolism of HTG VLDL. Reduced whole plasma levels of apo C-II and C-III in the postprandial state have also been reported previously (51). It has been speculated 

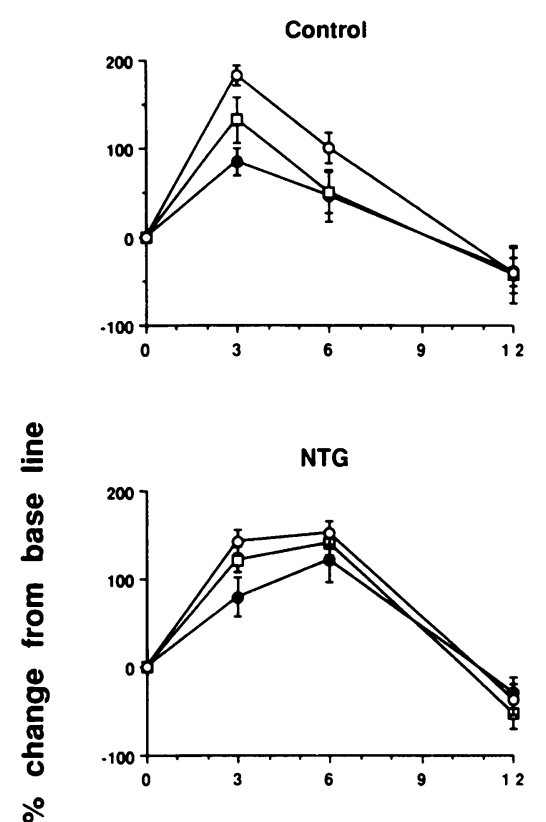

ஓ

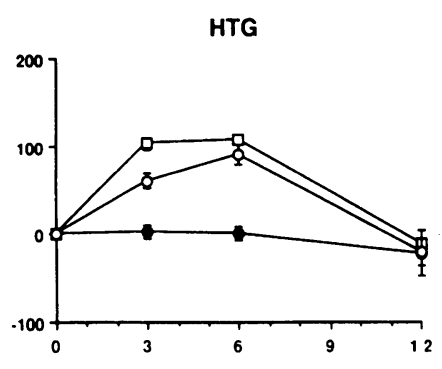

Time (hour)
Figure 2. Line plots of the relative changes of apo B-100 and apo B-48 (named apo B together), triglycerides, and apo C-II in Sf $60-400$ lipoproteins in response to the oral fat load in controls, normotriglyceridemic $(N T G)$ patients, and hypertriglyceridemic $(H T G)$ patients. $\circ$, Triglycerides; $\square$, apo B; a, apo C-II.

that apo Cs leave the plasma compartment together with the TGRL remnants which are formed during lipolysis $(51,52)$.

Quantification of apo C-II and C-III in the TGRL fractions showed that the concentrations of these apolipoproteins in

large and small TGRL in NTG subjects tended to parallel the content of triglyceride, apo B-48, and apo B-100 in each fraction. This suggested a constant molar ratio between apo C-II, C-III, and B, and triglycerides. In contrast, the postprandial influx of apo B-48, apo B-100, and triglycerides into the Sf 60-400 fraction was not paralleled by increased levels of apo C-II and C-III in HTG subjects. Furthermore, the apo C-II and C-III concentrations of Sf 20-60 TGRL were reduced in HTG subjects. This indicates that HTG subjects acquire an altered apolipoprotein composition of Sf 20-60 and Sf 60-400 lipoproteins during alimentary lipemia.

Recently, Iriyama et al. (53) suggested that the capacity of HDL for donating apo Cs to TGRL is limited in experimental hypertriglyceridemia. It can thus be speculated that a relative deficiency of apo C-II and C-III ensues in the HTG TGRL as indicated in the present study. The implication would be that the apo $\mathrm{C}$ content of plasma HDL that can be transferred to postprandial TGRL may influence the metabolism of HTG TGRL particles. Assuming that the absence of any increase in the concentration of apo B-48 in the Sf 20-60 fraction in HTG subjects is a sign of reduced conversion of large chylomicron remnants to smaller remnant species, this disturbance may partly depend on excessive unmasking of apo $\mathrm{E}$, due to low levels of apo C-III, with a subsequent increase in receptor mediated uptake of large chylomicron remnants (6-9). Furthermore, the accumulation of large TGRL might also be secondary to decreased availability of apo C-II, the cofactor for LPL, with effects on the delipidation of the large TGRL species.

In conclusion, the present study demonstrates that postprandial triglyceridemia is not solely accounted for by the generation of intestinally derived chylomicrons and chylomicron remnants. A major contribution of presumably liver-derived TGRL was seen in all study groups. Importantly, the TGRL of the HTG patients were shown to acquire an abnormal apolipoprotein composition during alimentary lipemia. The elevated plasma levels and the altered composition of large TGRL during alimentary lipemia in HTG individuals influence the metabolism of cholesterol-rich smaller lipoproteins particles (chylomicron remnants and VLDL) which are presumably involved in atherogenesis (54).

Table VI. Relations of Areas under the Curve for Plasma Measurements of Apolipoprotein B-48 and B-100 in Sf 60-400 and Sf 20-60 Lipoprotein Fractions to Postheparin Plasma Lipoprotein Lipase and Hepatic Lipase Activities

\begin{tabular}{|c|c|c|c|c|c|c|c|c|}
\hline & \multicolumn{4}{|c|}{ AUC Sf $60-400$} & \multicolumn{4}{|c|}{ AUC Sf $20-60$} \\
\hline & \multicolumn{2}{|c|}{ Apo B-48 } & \multicolumn{2}{|c|}{ Apo B-100 } & \multicolumn{2}{|c|}{ Apo B-48 } & \multicolumn{2}{|c|}{ Apo B-100 } \\
\hline & LPL & $\mathrm{HL}$ & LPL & $\mathrm{HL}$ & LPL & $\mathrm{HL}$ & LPL & HL \\
\hline \multicolumn{9}{|l|}{ Controls } \\
\hline$n=10$ & -0.413 & 0.363 & -0.306 & 0.525 & -0.185 & 0.155 & -0.273 & 0.491 \\
\hline \multicolumn{9}{|c|}{ NTG patients } \\
\hline$n=17$ & 0.202 & 0.178 & 0.182 & 0.116 & -0.170 & $0.569^{*}$ & -0.050 & 0.232 \\
\hline \multicolumn{9}{|c|}{ HTG patients } \\
\hline$n=15$ & -0.018 & 0.397 & 0.258 & $0.654^{*}$ & -0.225 & -0.282 & 0.154 & 0.484 \\
\hline \multicolumn{9}{|l|}{ All } \\
\hline$n=32$ & $-0.366^{*}$ & $0.387^{*}$ & $-0.321^{*}$ & $0.391^{*}$ & -0.273 & 0.016 & -0.258 & $0.505^{\ddagger}$ \\
\hline
\end{tabular}

Pearson correlation coefficients.

${ }^{*} P<0.05 ;{ }^{\ddagger} P<0.01$. 


\section{Acknowledgments}

This study was supported by grants from the Swedish Medical Research Council $(204,727$, and 8691), the Swedish Heart-Lung Foundation, the Knut and Alice Wallenberg Foundation, the Torsten and Ragnar Söderberg Foundation, the Foundation for Old Servants, the King Gustaf V 80th Birthday Fund, the Professor Nanna Svartz' Fund, the Swedish Society for Medical Research (Karolinska Institute), the Swedish Medical Society, the Swedish Margarine Industry Fund for Research on Nutrition, and the Heart and Stroke Foundation of Ontario. Dr. Karpe has research fellowships from the Swedish Heart-Lung foundation and Förenade Liv Insurance Company. Dr. Hamsten is career investigator of the Swedish Heart-Lung Foundation.

\section{References}

1. Hoeg, J. M., D. D. Sviridov, D. E. Tennyson, S. J. Demosky, Jr., M. S. Meng, D. Bojanovski, I. G. Safonova, V. S. Repin, M. B. Kuberger, V. N. Smirnov, et al. 1990. Both apolipoproteins B-48 and B-100 are synthesized and secreted by the human intestine. J. Lipid Res. 31:1761-1769.

2. Redgrave, T. G. 1970. Formation of cholesteryl ester-rich particulate lipid during metabolism of chylomicrons. J. Clin. Invest. 49:465-471.

3. Havel, R. J., J. P. Kane, and M. L. Kashyap. 1973. Interchange of apolipoproteins between chylomicrons and high density lipoproteins during alimentary lipemia in man. J. Clin. Invest. 52:32-38.

4. Taskinen, M.-R., and T. Kuusi. 1987. Enzymes involved in triglyceride hydrolysis. In Lipoprotein Metabolism. J. Shepherd, editor. Baillére's Clinical Endocrinology and Metabolism, vol. 1, No. 3. Baillére Tindall, London. 639666.

5. Ginsberg, H. N., N.-A. Le, I. J. Goldberg, J. C. Gibson, A. Rubinstein, P. Wang-Iversen, R. Norum, and W. V. Brown. 1986. Apolipoprotein B metabolism in subjects with deficiency of apolipoproteins C-III and A-I. J. Clin. Invest. 78:1287-1295.

6. Shelburne, F., J. Hanks, W. Meyers, and S. Quarfordt. 1980. Effect of apoproteins on hepatic uptake of triglyceride emulsions in the rat. J. Clin. Invest. 65:652-658.

7. Windler, E., and R. J. Havel. 1985. Inhibitory effect of C apolipoproteins from rats and humans on the uptake of triglyceride-rich lipoproteins and their remnants by the perfused liver. J. Lipid Res. 26:556-565.

8. Kowal, R. C., J. Herz, K. H. Weisgraber, R. W. Mahley, M. C. Brown, and J. L. Goldstein. 1990. Opposing effects of apolipoproteins $E$ and $C$ on lipoprotein binding to low density lipoprotein receptor-related protein. J. Biol. Chem. 265:10771-10779.

9. Weisgraber, K. H., R. W. Mahley, R. C. Kowal, J. Herz, J. L. Goldstein, and M. S. Brown. 1990. Apolipoprotein C-I modulates the interaction of apolipoprotein $E$ with $\beta$-migrating very low density lipoproteins ( $\beta$-VLDL) and inhibits binding of $\beta$-VLDL to low density lipoprotein receptor-related protein. J. Biol. Chem. 265:22453-22459.

10. Gianturco, S. H., A. M. Gotto, Jr., and W. A. Bradley. 1985. Hypertriglyceridemia: lipoprotein receptors and atherosclerosis. Adv. Exp. Med. Biol. 183:4771.

11. Beisiegel, U., W. Weber, G. Ihrke, J. Herz, and K. K. Stanley. 1989. The LDL receptor related protein, $\mathrm{LRP}$, is an apolipoprotein E-binding protein. $\mathrm{Na}$ ture (Lond.). 341:162-164.

12. Hazzard, W. R., and E. L. Bierman. 1976. Delayed clearance of chylomicron remnants following vitamin-A-containing oral fat loads in broad- $\beta$ disease (type III hyperlipoproteinemia). Metab. Clin. Exp. 25:777-801.

13. Weintraub, M. S., S. Eisenberg, and J. L. Breslow. 1987. Dietary fat clearance in normal subjects is regulated by genetic variation in apolipoprotein $\mathrm{E} . J$. Clin. Invest. 80:1571-1577.

14. Zilversmit, D. B. 1979. Atherosclerosis: a postprandial phenomenon. Circulation. 60:473-485.

15. Cortner, J. A., P. M. Coates, N.-A. Le, D. R. Cryer, M. C. Ragni, A. Faulkner, and T. Langer. 1987. Kinetics of chylomicron remnant clearance in normal and hyperlipoproteinemic subjects. J. Lipid Res. 28:195-206.

16. Weintraub, M. S., S. Eisenberg, and J. L. Breslow. 1987. Different patterns of postprandial lipoprotein metabolism in normals, type IIa, type III, and type IV hyperlipoproteinemic individuals. Effect of treatment with cholestyramine and gemfibrozil. J. Clin. Invest. 79:1110-1119.

17. Berr, F. 1992. Characterization of chylomicron remnant clearance by retinyl palmitate label in normal humans. J. Lipid Res. 33:915-930.

18. Simpson, H. S., C. M. Williamson, T. Olivecrona, S. Pringle, J. Maclean, A. R. Lorimer, F. Bonnefous, Y. Bogaievsky, C. J. Packard, and J. Shepherd. 1990. Postprandial lipemia, fenofibrate and coronary artery disease. Atherosclerosis. 85:193-202.
19. Groot, P. H. E., W. A. H. J. van Stiphout, X. H. Krauss, H. Jansen, A. van Tol, E. van Ramshorst, S. Chin-On, A. Hofman, S. R. Cresswell, and L. Havekes. 1991. Postprandial lipoprotein metabolism in normolipidemic men with and without coronary artery disease. Arterioscler. Thromb. 11:653-662.

20. Hamsten, A., G. Walldius, A. Szamosi, G. Dahlén, and U. de Faire. 1986. Relationship of angiographically defined coronary artery disease to serum lipoproteins and apolipoproteins in young survivors of myocardial infarction. Circulation. 73:1097-1110.

21. Hamsten, A. 1986. Studies on myocardial infarction at young age. Metabolic, haemostatic and familial factors in post-infarction patients below the age of 45. Ph.D. thesis. Karolinska Institute, Stockholm. 1-91.

22. Cohn, J. S., J. R. McNamara, S. D. Cohn, J. M. Ordovas, and E. J. Schaefer. 1988. Plasma apolipoprotein changes in the triglyceride-rich lipoprotein fraction of human subjects fed a fat-rich meal. J. Lipid Res. 29:925-936.

23. Scientific tables. Documenta Geigy. 1970. 7th edition. K. Diem and C. Lentner, editors. J. R. Geigy S. A., Basel. p. 537.

24. Redgrave, T. G., D. C. K. Roberts, and C. E. West. 1975. Separation of plasma lipoproteins by density gradient ultracentrifugation. Anal. Biochem. 65:42-49.

25. Poapst, M., K. Uffelman, and G. Steiner. 1987. The chromogenicity and quantitation of apo B-100 and apo B-48 of human plasma lipoproteins on analytical SDS gel electrophoresis. Atherosclerosis. 65:75-88.

26. Kane, J. P., D. A. Hardman, and H. E. Paulus. 1980. Heterogeneity of apolipoprotein B. Isolation of a new species from human chylomicrons. Proc. Natl. Acad. Sci. USA. 77:2465-2469.

27. Lowry, O. H., N. J. Rosebrough, A. L. Farr, and R. J. Randall. 1951. Protein measurement with the Folin phenol reagent. J. Biol. Chem. 193:265-275.

28. Herbert, P. N., R. S. Shulman, R. I. Levy, and D. S. Fredrickson. 1973. Fractionation of the c-apoproteins from human plasma very low density lipoproteins. J. Biol. Chem. 248:4941-4946.

29. Reardon, M. F., M. E. Poapst, K. D. Uffelman, and G. Steiner 1981. Improved method for quantitation of B apoprotein in plasma lipoproteins by electroimmunoassay. Clin. Chem. 27:892-895.

30. Holmquist, L. 1980. Quantification of human serum very low density apolipoproteins C-I, C-II, C-III and E by enzyme immunoassay. J. Immunol. Methods. 34:243-251.

31. Anuzzi, G., L. Holmquist, and L. A. Carlson. 1989. Concentrations of apolipoproteins B, C-I, C-II, C-III, E and lipids in serum and serum apolipoproteins in normal subjects during alimentary lipemia. Scand. J. Clin. Lab. Invest. 49:73-81

32. Kunkel, L. M., K. D. Smith, S. H. Boyer, D. S. Borgaonkar, S. S. Wankel, W. R. Beg, H. W. Jones, and J. M. Rary. 1977. Analysis of human Y-chromosome specific reiterated DNA in chromosome variants. Proc. Natl. Acad. Sci. USA. 74:1245-1249.

33. Hixson, J. E., and D. T. Vernier. 1990. Restriction isotyping of human apolipoprotein E by gene amplification and cleavage with Hhal. J. Lipid Res. 31:545-548.

34. Myant, N. B., J. J. Gallagher, B. L. Knight, S. N. McCarthy, J. Frostegård, J. Nilsson, A. Hamsten, P. Talmud, and S. E. Humphries. 1991. Clinical signs of familial hypercholesterolemia in patients with familial defective apolipoprotein B-100 and normal low density lipoprotein receptor function. Arterioscler. Thromb. 11:691-703.

35. Carlson, K. 1973. Lipoprotein fractionation. J. Clin. Pathol. (Lond.). 5(Suppl. 26):32-37.

36. Carlson, L. A. 1963. Determination of serum triglycerides. J. Atheroscler. Res. 3:334-336.

37. Zlatkis, A., B. Zak, and A. Boyle. 1953. A new method for direct determination of serum cholesterol. J. Lab. Clin. Med. 41:486-492.

38. Fletcher, M. J. 1968. A colorimetric method for estimating serum triglycerides. Clin. Chim. Acta. 22:393-397.

39. Peterson, J., B. E. Bihain, G. Bengtsson-Olivecrona, R. J. Deckelbaum, Y. A. Carpentier, and T. Olivecrona. 1990. Fatty acid control of lipoprotein lipase: a link between energy metabolism and lipid transport. Proc. Natl. Acad. Sci. USA. 87:909-913.

40. Reaven, G. M., R. Bernstein, B. Davis, and J. M. Olefsky. 1976. Nonketotic diabetes mellitus: insulin deficiency or insulin resistance. Am. J. Med. 60:80-88.

41. Genest, J., A. Sniderman, K. Cianflone, B. Teng, S. Wacholder, Y. Marcel, and P. Kwiterovich, Jr. 1986. Hyperapobetalipoproteinemia: plasma lipoprotein responses to oral fat load. Arteriosclerosis. 6:297-304.

42. Packard, C. J., A. Munro, A. R. Lorimer, A. M. Gotto, Jr., and J. Shepherd. 1984. Metabolism of apolipoprotein B in large triglyceride-rich very low density lipoproteins of normal and hypertriglyceridemic subjects. J. Clin. Invest. 74:2178-2193.

43. Brunzell, J. D., W. R. Hazzard, D. Porte, Jr., and E. L. Bierman. 1973. Evidence for a common, saturable, triglyceride removal mechanism for chylomicrons and very low density lipoproteins. J. Clin. Invest. 52:1578-1585.

44. Cohn, J. S., D. A. Wagner, S. D. Cohn, J. S. Millar, and E. J. Schaefer. 1990. Measurement of very low density lipoprotein and low density lipoprotein 
apolipoprotein (apo) B-100 and high density lipoprotein apo A-I production in human subjects using deuterated leucine. J. Clin. Invest. 85:804-811.

45. Foster, D. M., P. H. Hugh, and R. Barrett. 1990. Considerations in designing and analyzing data from apo B turnover studies. In Hypercholesterolemia, Hypocholesterolemia and Hypertriglyceridemia. C. L. Malmendier, editor. Plenum Publishing Corp., New York. pp. 201-211.

46. Eisenberg, S., D. Gavish, Y. Oschry, M. Fainaru, and R. J. Deckelbaum. 1984. Abnormalities in very low, low and high density lipoproteins in hypertriglyceridemia. J. Clin. Invest. 74:470-482.

47. Olivecrona, T., and G. Bengtsson-Olivecrona. 1990. Lipoprotein lipase and hepatic lipase. Curr. Opin. Lipidol. 1:222-230.

48. Carlson, L. A., L. Holmquist, and P. Nilsson-Ehle. 1986. Deficiency of hepatic lipase in postheparin plasma in familial hyper- $\alpha$-triglycericemia. Acta Med. Scand. 219:435-447.

49. Kane, J. P., T. Sata, R. L. Hamilton, and R. J. Havel. 1975. Apoprotein composition of very low density lipoproteins of human serum. J. Clin. Invest. $56: 1622-1634$
50. Kashyap, M., L. S. Srivastava, C. Y. Chen, G. Perisutti, M. Campbell, R. F. Lutmer, and C. J. Glueck. 1977. Radioimmunoassay of human apolipoprotein C-II. A study in normal and hypertriglyceridemic subjects. J. Clin. Invest. 60:171-180.

51. Barr, S. I., B. A. Kottke, and S. J. T. Mao. 1985. Postprandial distribution of apolipoproteins C-II and C-III in normal subjects and patients with mild hypertriglyceridemia: comparison of meals containing corn oil and medium-chain triglyceride oil. Metab. Clin. Exp. 34:983-992.

52. Nestel, P. J., M. W. Huff, T. Billington, and N. H. Fidge. 1982. Changes in the plasma lipoprotein distribution of apolipoproteins C-II, C-III, C-III ${ }_{2}$ and apolipoprotein B after heparin-induced lipolysis. Biochim. Biophys. Acta. 712:94-102.

53. Iriyama, K., H. Tonouchi, T. Azuma, H. Suzuki, and Y. A. Carpentier. 1991. Capacity of high-density lipoprotein for donating apolipoproteins to fat particles in hypertriglyceridemia induced by fat infusion. Nutrition. 7:355-357.

54. Eisenberg, S. 1990. Metabolism of apolipoproteins and lipoproteins. Curr. Opin. Lipidol. 1:205-215. 